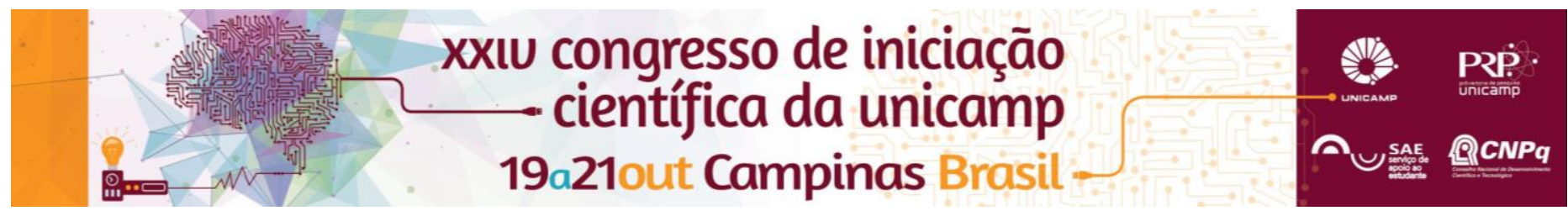

\title{
Entre o revólver e o batom: mulheres no policiamento ostensivo no Estado de São Paulo, uma questão de gênero.
}

\author{
Vitória Affonso Ferreira*, Susana Soares Branco Durão.
}

\begin{abstract}
Resumo
A partir de uma pesquisa de campo e realização de 20 entrevistas esse projeto irá discutir, como um de seus principais aparatos do Estado, a Polícia Militar, se apresenta publicamente, particularmente frente à pesquisa científica. Assim, perceberemos que o imaginário que os policiais criam sobre a sociedade, e em particular sobre sua noção da pesquisa antropológica/sociológica, criando sobre eles a necessidade de controle de sua imagem, movimento ao qual chamamos de máscara. A nossa reflexão teórico-metodológica é embasada em questões de gênero focando em como isto vai influênciar nas noções de masculinidade na Polícia Militar de Campinas-SP.
\end{abstract}

\section{Palavras-chave:}

Polícia Militar, Gênero, Máscaras do Estado.

\section{Introdução}

Esta pesquisa buscou, inicialmente, realizar uma etnografia acerca das trajetórias e vivências de mulheres policiais na cidade de Campinas-SP. Entretanto, devido a uma série de percalços de caráter institucional-burocrático nosso objetivo inicial foi alterado, para um escopo reflexivo e metodológico acerca do trabalho de campo antropológico.

Para isso nos basearemos em Mitchell ${ }^{1}$ e seu conceito de máscaras do Estado, enquanto as questões acerca de gênero terão suas reflexões baseadas principalmente na revisão da tese de Souza².

Em suma, esse trabalho será constituído em três partes distintas, a primeira onde revisaremos a bibliografia lida analisando-a junto de nosso trabalho, em segundo mostraremos como as máscaras do Estado se espalham para seus aparatos, no caso a Polícia Militar (PM), criando um complexo jogo de máscaras. $E$ por último partiremos para uma análise de como a produção de imagem é importante para os policiais e como ela está construída sobre a masculinidade, tudo isso permeado por reflexões metodológicas.

\section{Resultados e Discussão}

Com base na bibliografia lida constatamos que a maioria da literatura sobre gênero na polícia aborda o mundo policial de uma forma muito parecida: partindo de uma contextualização da formação da polícia brasileira, seguindo para uma regionalidade, e por fim discutindo mais profundamente sobre a posição das mulheres na instituição. Seus argumentos oscilam em duas formas: relação de poder ou representações sociais, sendo gênero uma categoria sempre tratada de forma binária (MOORE ${ }^{3}$ ). Porém, a tese de Souza, sobre as mulheres policiais em São Paulo, nos chamou a atenção, por ter extrapolado a bibliografia e também por ter sido objeto de discussão durante nosso trabalho de campo. A partir dela nós pudemos elaborar 0 argumento central desse projeto, pensando - baseado em Mitchell - a conexão Estadosociedade a partir de máscaras: como o Estado dilui sua forma em seus aparatos, tornando difícil à pesquisadora a sua conceituação e identificação? Essa questão nasceu durante o campo devido ao grande número de situações que os elementos da PM, na maioria das vezes, criavam durante essa pesquisa gerando um movimento de abertura e fechamento do campo, criando assim uma série de tensões e impasses, bem como possibilidades, na DOI: 10.19146/pibic-2016-50723 pesquisa. Percebemos, portanto, que a PM também encontra suas próprias máscaras, e a que se destacou mais foi sobre a produção de sua imagem. Constatamos que ela está conectada com a visão do policial, encontrada no imaginário da sociedade: fechado, que persegue bandido e o prende, que aparece nas situações de conflito, adjetivos e situações conectados ao universo masculino. Assim sendo, a PM tem como exigência da sociedade, como dos próprios policiais, o reconhecimento de sua profissão sob a máscara da construção da masculinidade. Com isso, introduzimos, a partir das relações estabelecidas em campo, uma novidade na abordagem de gênero nos estudos policiais: analisamos a situação das mulheres policiais sob a ótica da construção da masculinidade, o que isso significa no universo policial e como esse construto é sustentado por outros setores como o Estado e a mídia.

\section{Conclusões}

Concluímos, com esses percalços no trabalho de campo, as dificuldades existentes quando se tenta adentrar os aparatos institucionais do Estado. Além disso a necessidade de serem realizadas pesquisas sobre a Polícia Militar que reflitam a partir de uma dimensão interativa e reflexiva, evitando desse modo o distanciamento e alteridade radical que, do nosso ponto de vista, se mantém na maioria dos trabalhos sobre a instituição. Por fim, como as interações em campo implicaram diretamente na questão de gênero que pudemos perceber, assim como a importância simbólica dada ao masculino em todas as entrevistas.

\section{Agradecimentos}

Agradeço à Polícia Militar do estado de São Paulo, em especial aos policiais de Campinas; ao CNPQ pelo financiamento dessa pesquisa; à Prof $^{-}{ }^{-} r^{\text {a }}$ Susana Durão pela orientação e paciência; e aos meus familiares e amigos por estarem comigo em todos os momentos.

${ }^{1}$ MITCHELL, Timothy. Society, Economy, and the State Effect. State/Culture: State-Formation after the Cultural Turn. In: STEINMETZ, G. pp. 169-186. Ithaca, NY and London: Cornell University Press, 1999.

2 SOUZA,Marcos Santana de. Sou policial, mas sou mulher: gênero e representações sociais na polícia militar de São Paulo. Tese de Doutorado em Ciências Sociais Universidade Estadual de Campinas. São Paulo - SP. 2014. ${ }^{3}$ MOORE, Henrietta. Compreendendo Sexo e Gênero. In: Undestanding sex and gender. In: INGOLD, Tim. pp. 813-830. Companion Encyclopedia of Antrhopology. Londres. Trad: Júlio Assis Simoões. 